Research article

\title{
Shorter courses of parenteral antibiotic therapy do not appear to influence response rates for children with acute hematogenous osteomyelitis: a systematic review Nicole Le Saux*1,2, Andrew Howard ${ }^{3}$, Nicholas J Barrowman 1,4,5, Isabelle Gaboury4, Margaret Sampson ${ }^{4}$ and David Moher ${ }^{1,4}$
}

Address: ${ }^{1}$ Department of Pediatrics, University of Ottawa, Ottawa, Canada, ${ }^{2}$ Division of Infectious Diseases, Children's' Hospital of Eastern Ontario, Canada, ${ }^{3}$ Division of Orthopedics, Hospital for Sick Children, Toronto, Ontario, Canada, ${ }^{4}$ Chalmers Research Group, Children's Hospital of Eastern Ontario Research Institute, Canada and ${ }^{5}$ School of Mathematics and Statistics, Carleton University, Canada

E-mail: Nicole Le Saux* - lesaux@cheo.on.ca; Andrew Howard - andrew.howard@sickkids.ca;

Nicholas J Barrowman - nbarrowman@cheo.on.ca; Isabelle Gaboury - igaboury@cheo.on.ca; Margaret Sampson - msampson@uottawa.ca; David Moher -dmoher@uottawa.ca

${ }^{*}$ Corresponding author

Published: 14 August 2002

BMC Infectious Diseases 2002, 2:16

This article is available from: http://www.biomedcentral.com/I47I-2334/2/16

(C) 2002 Le Saux et al; licensee BioMed Central Ltd. This article is published in Open Access: verbatim copying and redistribution of this article are permitted in all media for any non-commercial purpose, provided this notice is preserved along with the article's original URL.
Received: 26 April 2002

Accepted: 14 August 2002

\begin{abstract}
Background: Acute hematogenous osteomyelitis (AHO) occurs primarily in children and is believed to evolve from bacteremia followed by localization of infection to the metaphysis of bones. Currently, there is no consensus on the route and duration of antimicrobial therapy to treat $\mathrm{AHO}$.

Methods: We conducted a systematic review of a short versus long course of treatment for AHO due primarily to Staphylococcus aureus in children aged 3 months to 16 years. We searched Medline, Embase and the Cochrane trials registry for controlled trials. Clinical cure rate at 6 months was the primary outcome variable, and groups receiving less than 7 days of intravenous therapy were compared with groups receiving one week or longer of intravenous antimicrobials.
\end{abstract}

Results: 12 eligible prospective studies, one of which was randomized, were identified. The overall cure rate at 6 months for the short course of intravenous therapy was $95.2 \%(95 \% \mathrm{Cl}=90.4,97.7)$ compared to $98.8 \%(95 \% \mathrm{Cl}=93.6,99.8)$ for the longer course of therapy. There was no significant difference in the duration of oral therapy between the two groups.

Conclusions: Given the potential increased morbidity and cost associated with longer courses of intravenous therapy, this finding should be confirmed through a randomized controlled equivalence trial.

\section{Background}

Acute hematogenous osteomyelitis (AHO) occurs mainly in children and is more common in males [1-3]. AHO is believed to evolve from bacteremia followed by localization of infection to the metaphysis of bones. Successful treatment of AHO is crucial for the prevention of morbidity and functional loss of the affected limb.

Currently, there is no consensus on the route and duration of antimicrobial therapy to treat AHO. The suggested 
duration of intravenous therapy ranges from 3 days to 4 to 6 weeks. One general pediatric textbook describes 7 days of parenteral therapy as standard, [4] whereas a pediatric infectious diseases textbook states that the usual duration of therapy is 4 to 8 weeks with a change to oral medication permissible when signs of local inflammation has resolved [5]. A standard orthopedic textbook suggests intravenous therapy for 5 days followed by oral therapy for 4 to 6 weeks for "typical" cases [6].

Given the paucity of randomized controlled trial evidence to guide clinicians in the management of children with $\mathrm{AHO}$, they have typically relied on data presented in observational studies. The vast majority of these studies have used a cohort design. Here, a group of children diagnosed with $\mathrm{AHO}$ are identified and treated using antibiotic therapy. The results are usually reported as successful response rates following a specified period of treatment (e.g., 14 days).

Two studies, each including over 100 children, suggest at least 3 weeks of intravenous antimicrobial therapy for the treatment of AHO in children. In these two studies, success rates of $82 \%$ and $81 \%$ were observed in children treated with intravenous antibiotics for less than 21 days $[7,8]$. There is, however, wide variation between studies regarding failure rates according to treatment duration. A series of smaller studies quoting 1 to 52 days of parenteral antimicrobial therapy have reported success rates ranging from $81 \%$ to $100 \%$ [9-25]. The aim of our systematic review was to determine whether short courses (less than 1 week) of parenteral antimicrobial therapy show equivalent cure rates compared with longer courses (greater than 1 week) in children with AHO caused primarily by Staphylococcus aureus.

\section{Methods \\ Search strategy}

Medline and EMBASE were searched electronically to help identify relevant literature from January 1966 to April 2001. The Cochrane Controlled Trials Register, Cochrane Library was searched from 1981 to July 2000. There were no restrictions on language or publication status. The literature was monitored throughout the course of the project by periodically re-running the search in Medline and screening newly posted citations. (Please see additional file 1)

\section{Inclusion criteria}

Studies were included if they involved children between 3 months and 16 years of age. The clinical criteria used for the diagnosis of AHO was: (a) positive culture of Staphylococcus aureus from bone or periosteum; or (b) clinical signs of osteomyelitis and a concurrent positive blood culture; or (c) clinical signs and a compatible radiological study (nuclear scan or radiography). Clinical signs were to include swelling, warmth, tenderness and decreased ability to weight bear.

The study design had to meet 3 eligibility criteria: 1) the study had to be prospective cohort; 2) the intervention had to identify the antimicrobial and its route (parenteral or oral) and duration of therapy; and 3) the outcome after an average of 6 months of follow up had to be stated or inferable as clinical cure, failure or relapse.

\section{Study selection}

Titles and abstracts of each citation were downloaded to a reference database. Two authors (NLS, AH) independently screened each citation to determine whether to retain it. Potentially relevant citations were retrieved and then subjected to a relevance assessment using our eligibility criteria. Open consensus was used to settle differences.

\section{Data abstraction}

Once a study met the inclusion criteria, two members of the research team (NLS; $\mathrm{AH}$ ) independently abstracted data using structured data abstraction forms. We captured information about the report (e.g., language of publication), design (e.g., cohort), population (e.g., diagnosis), intervention (e.g., type of antibiotic), and primary outcome (e.g., response rates). If more than one cohort was present in a study, data from each cohort was abstracted separately. Disagreements were resolved by consensus.

\section{Data analysis}

Treatment of seven days or less of parenteral therapy was considered short course. In many institutions the, typical time required for defervescence, observation, and arrangement of follow-up is about seven days. We thought that this was a practical point at which to dichotomize for the purposes of analysis.

When all children are cured, normal theory based confidence intervals for the proportion cured are unavailable, and when cure rates are close to $100 \%$, normal theory based confidence intervals may provide poor approximations. To overcome these problems, Wilson score confidence intervals were computed [26]. Under the hypothesis of homogeneity of cure rates across cohorts, a fixed-effect estimate of the overall cure rate is provided by the total number of cured patients divided by the total number of patients. The same estimate is provided by an intercept-only logistic regression model. To test the homogeneity of cure rates, the residual deviance from the logistic regression model was compared to a chi-square distribution with degrees of freedom given by the number of cohorts minus one. 


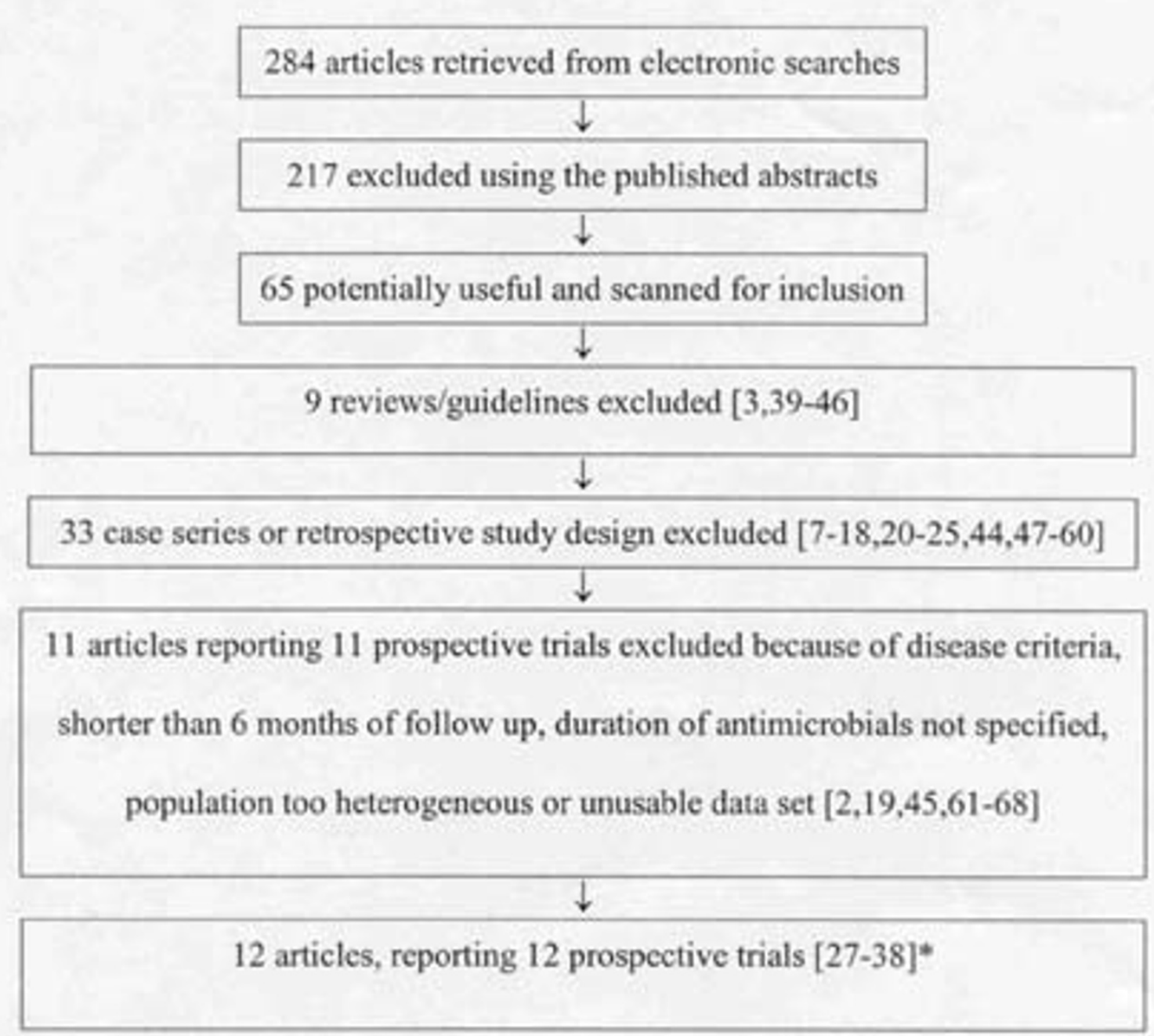

Figure I

Flow diagram outlining the results of literature search and review of studies retrieved.

*Kaplan [38] is not included in the analysis because it is methodologically dissimilar from the other cohorts

Cohorts with different treatments within the same study were analyzed as separate parallel groups. The difference between the overall cure rate under short- and long-term parenteral antimicrobial therapy was assessed using a ztest. Using the same methods, we performed a sub-group analysis comparing overall cure rates for beta-lactams and macrolides. The difference in mean length of oral therapy for cohorts that had short- and long-term parenteral antimicrobial therapy was assessed using a t-test. Unlike parallel-arm studies, where selective publication of statistically significant results may produce publication bias, quite different publication issues may apply to single-arm cohort studies. The funnel plot, often used to assess publication bias, is therefore not relevant in this review.

\section{Results}

A flow diagram of the search results is illustrated in Figure 1. Two hundred and eighty-four articles were identified initially. Of these, 57 articles were considered potentially relevant. Of these, 34 were small or mixed case series or had a retrospective study design. Of the remaining 23,11 
Table I: Studies which were excluded and the principle reason for exclusion

\begin{tabular}{|c|c|}
\hline Study & Reason For Exclusion \\
\hline Unkila-Kallio 1993 & Mainly epidemiologic data. Appears to be the cohort from which Peltola 1997 is drawn. \\
\hline Dones 1994 & Small prospective cohort of 4 patients evaluating teicoplanin. \\
\hline Nelson 1982 & $\begin{array}{l}\text { Study addressed bactericidal titers. Follow-up did not extend to } 6 \text { months although } \\
\text { reported cure rate was } 95 \% \text { with an average duration of } 5 \text { days of intravenous antimicrobi- } \\
\text { als. }\end{array}$ \\
\hline Beauvais 198I & $\begin{array}{l}\text { Addressed the use of pristinamycin orally. Data was not usable because group could not } \\
\text { be reliably separated for route and type of antimicrobial. }\end{array}$ \\
\hline Fleming 1970 & No follow-up data available. Trial focussed on microbiology and side effects of treatment. \\
\hline Nussinovitch 1997 & $\begin{array}{l}\text { Data on osteomyelitis cases alone could not be extracted. Maximum follow-up was about } \\
4 \text { months. Cure appeared to be } 95 \% \text { with mean duration of IV antibiotics of I } 3.7 \text { days. }\end{array}$ \\
\hline Walker 1973 & $\begin{array}{l}\text { Follow-up was } 4 \text { months. Mean duration of intravenous antimicrobials in } 14 \text { children was } \\
4.21 \text { days (range } 2-2 \text { I days) and cure was } 100 \% \text {. }\end{array}$ \\
\hline Bandelon 1988 & $\begin{array}{l}\text { Group of osteomyelitis and septic arthritis could not be separated with respect to length } \\
\text { of therapy or etiology. }\end{array}$ \\
\hline Kulhanjianv 1989 & Only 3 cases of osteomyelitis due to $S$. aureus. \\
\hline Aronoff 1986 & Of 9 children only I child had osteomyelitis alone. No follow-up. \\
\hline Learmonth 1984 & $\begin{array}{l}\text { Combined patients with septic arthritis and osteomyelitis. Could not extract data with } \\
\text { respect to } S \text {. aureus alone. }\end{array}$ \\
\hline
\end{tabular}

studies that appeared to be prospective cohorts had either unusable data, short follow-up or the duration of antimicrobial could not be discerned from the data presented (Table 1). Of the remaining 12 studies, 11 that were of a prospective design were included in the systematic review [27-37]. In some cases, only a subset of patients were eligible for inclusion (see notes in Table 2). We excluded one study of 25 children [38] as it was a different study archi- tecture. It is inappropriate to combine estimates of effectiveness (i.e., cure rates) from different study types.

The range of duration of parenteral antimicrobial therapy was 3 to 28 days. Table 2 shows details of the 12 cohort studies that were used in the analysis. Figure 2 graphically illustrates the cure rate versus the duration of parenteral antimicrobial therapy for these cohorts. (Figure 2)

Table 2: Description of studies and the associated cure rates

\begin{tabular}{|c|c|c|c|c|c|c|c|c|}
\hline Author & $\begin{array}{l}\text { Publication } \\
\text { year }\end{array}$ & $\begin{array}{l}\text { Sample } \\
\text { sizel }\end{array}$ & $\begin{array}{l}\text { S. aureus } \\
\text { positive } \\
\text { culture (\%) }\end{array}$ & $\begin{array}{l}\text { Parenteral (IV) } \\
\text { antimicrobial }\end{array}$ & $\begin{array}{l}\text { Days of IV } \\
\text { treatment } \\
\text { Mean } \\
\text { (range) }\end{array}$ & $\begin{array}{l}\text { Oral } \\
\text { antimicrobial }\end{array}$ & $\begin{array}{l}\text { Days of oral } \\
\text { treatment } \\
\text { Mean } \\
\text { (range) }\end{array}$ & $\begin{array}{l}\text { Cure rate \% } \\
\text { (Cl) }\end{array}$ \\
\hline
\end{tabular}

Long Course

\begin{tabular}{|c|c|c|c|c|c|c|c|c|}
\hline Kolyvas ${ }^{2}$ & 1980 & 5 & $50.0^{3}$ & $\begin{array}{l}\text { Cephradine +/- } \\
\text { Ampicillin }\end{array}$ & $28(28-28)$ & $\begin{array}{l}\text { Cephradine or } \\
\text { Cloxacillin }\end{array}$ & $18(14-35)$ & $\begin{array}{l}100 \\
(67,100)\end{array}$ \\
\hline Tetzlaff & 1978 & 18 & 100.0 & $\begin{array}{l}\text { Methicillin or } \\
\text { Cefazolin }\end{array}$ & $8(7-13)$ & $\begin{array}{l}\text { Cephalexin or } \\
\text { Penicillin V }\end{array}$ & $20(13-42)$ & $\begin{array}{l}94 \\
(77,100)\end{array}$ \\
\hline Bryson & 1979 & 18 & 100.0 & $\begin{array}{l}\text { Oxacillin or } \\
\text { Methicillin }\end{array}$ & $7(5-14)$ & Dicloxacillin & N/A $(28-56)$ & $\begin{array}{l}100 \\
(89,100)\end{array}$ \\
\hline Rodriguez & 1977 & 21 & 90.5 & Clindamycin 4 & $25(2 \mathrm{I}-28)$ & Clindamycin & $42(42-42)$ & $\begin{array}{l}100 \\
(91,100)\end{array}$ \\
\hline Prober & 1979 & 22 & 100.0 & $\begin{array}{l}\text { Nafcillin or } \\
\text { Methicillin }\end{array}$ & $14^{5}(4-28)$ & Dicloxacillin & $28^{3}(\mathrm{~N} / \mathrm{A})$ & $\begin{array}{l}100 \\
(91,100)\end{array}$ \\
\hline
\end{tabular}

Short Course 
Table 2: Description of studies and the associated cure rates (Continued)

\begin{tabular}{|c|c|c|c|c|c|c|c|c|}
\hline Kolyvas ${ }^{2}$ & 1980 & 5 & $50.0^{3}$ & & $3(\mathrm{~N} / \mathrm{A})$ & $\begin{array}{l}\text { Cephradine or } \\
\text { Cloxacillin }\end{array}$ & $42^{3}(39-60)^{3}$ & $\begin{array}{l}100 \\
(67,100)\end{array}$ \\
\hline Refass $^{6}$ & 1989 & 6 & 98.9 & Cloxacillin & N/A (5-6) & Flucloxacillin & N/A $(7-200)^{3}$ & $\begin{array}{l}100 \\
(72,100)\end{array}$ \\
\hline Freij & 1987 & 8 & 100.0 & $\begin{array}{l}\text { Imipenem + } \\
\text { Cilastatin }\end{array}$ & $5.5(4-9)$ & $\begin{array}{l}\text { Cefaclor or } \\
\text { Dicloxacillin or } \\
\text { Cephalexin or } \\
\text { Bacampicillin or } \\
\text { Penicillin V }\end{array}$ & $15(13-19)$ & $\begin{array}{l}88 \\
(55,100)\end{array}$ \\
\hline Feigin 7 & 1975 & II & 72.7 & Clindamycin & $6(3-13)$ & Clindamycin & $42^{5}(\mathrm{~N} / \mathrm{A})$ & $\begin{array}{l}91 \\
(65,100)\end{array}$ \\
\hline Geddes $^{8}$ & 1977 & 18 & $65.0^{3}$ & Clindamycin & $6^{3}(\mathrm{~N} / \mathrm{A})$ & Clindamycin & $90^{3}(\mathrm{~N} / \mathrm{A})$ & $\begin{array}{l}94 \\
(77,100)\end{array}$ \\
\hline Cole ${ }^{9}$ & 1982 & 48 & 94.5 & $\begin{array}{l}\text { Cloxacillin or } \\
\text { Cephalothin }\end{array}$ & $3(2-5)$ & $\begin{array}{l}\text { Cloxacillin or } \\
\text { Cephalexin }\end{array}$ & $39(37-40)$ & $\begin{array}{l}92 \\
(81,97)\end{array}$ \\
\hline Peltola & 1997 & 50 & 100.0 & $\begin{array}{l}\text { Cephradine or } \\
\text { Cephalothin or } \\
\text { Clindamycin }\end{array}$ & $4(4-6)$ & $\begin{array}{l}\text { Cefadroxil or } \\
\text { Clindamycin }\end{array}$ & $19(17-19)$ & $\begin{array}{l}100 \\
(96,100)\end{array}$ \\
\hline
\end{tabular}

\footnotetext{
I Includes cases that were due to Staphylococcus aureus and those who were culture negative 2 Included only the cases that had osteomyelitis alone or had contiguous arthritis and osteomyelitis. ${ }^{3}$ Estimated value. ${ }^{4}$ Clindamycin is the only macrolide studied - all other antimicrobials mentioned are beta-lactams. ${ }^{5}$ Median reported. 6 Only the 6 patients who clearly met the diagnostic criteria were included. 7 Data abstracted from the II cases of osteomyelitis (8 of whom had S. aureus). ${ }^{8}$ Only data for the 18 children with acute osteomyelitis from the study were included. Some of these may only have received oral medication. 9 Data from the 48 patients for whom there was follow-up of greater than 6 months.
}

The 7 cohorts that had less than 7 days of intravenous therapy $(n=146)$ had a pooled cure rate of $95.2 \%(95 \%$ confidence interval: 90.4, 97.7) [28-32,35,37]. There was no significant heterogeneity among their cure rates (chisquare $=8.2$ on $6 \mathrm{df}, \mathrm{p}=0.224$ ), indicating that the variation in cure rates could be attributed to sampling error.

The 5 cohorts who had a duration of intravenous therapy of 7 days or longer $(n=84)$ had a pooled cure rate of $98.8 \%(95 \%$ confidence interval; 93.6, 99.8) $[27,31,33,34,36]$. There was no significant heterogeneity among these cure rates (chi-square $=3.1$ on $4 \mathrm{df}, \mathrm{p}=$ 0.537). Pooling all of the cohorts regardless of duration of intravenous therapy, there was no significant heterogeneity among cure rates (chi-square $=13.7$ on $11 \mathrm{df}$, $\mathrm{p}=$ $0.248)$. The fixed effects model gave a pooled cure rate of 96.5\% (95\% confidence interval; 93.3, 98.2). There was no significant difference in the cure rate between the two groups (z-test p-value 0.838 ).

Comparing beta-lactams and macrolides, there was no significant heterogeneity within either group (betalactams; chi square $=7.3$ on $7 \mathrm{df}, \mathrm{p}=0.394$. macrolides; chi square $=5.2$ on $4 \mathrm{df}, \mathrm{p}=0.159$ ). The pooled cure rate for beta-lactams was $95.4 \%$ (95\% confidence interval; $90.3,97.9)$ under a fixed effects model. The pooled cure rate for macrolides was $98.0 \%$ ( $95 \%$ confidence interval;
$93.0,99.4)$. There was no significant difference in the cure rate between the two groups (z-test p-value 0.286).

Since the total duration of antimicrobial therapy (i.e., parenteral plus oral) can affect the cure rate, we also looked at the duration of oral therapy. For the cohorts that had less than 1 week of parenteral therapy, the range of duration of oral therapy was 15 to 39 days with a mean of 32 days $[28-31,35,37]$. We could not reliably determine the mean number of days of oral antimicrobials from one study [32]. For the cohorts that were given a longer duration of intravenous therapy, the range of duration of oral therapy was 18 to 56 days with a mean of 33 days $[27,31,33,34,36]$. There was no significant difference in the duration of oral therapy between the two groups ( $t$ test p-value 0.888).

Among the group who had short-term antimicrobials, the percentage of children that had surgery ranged from $30 \%$ to 'routine' or probably over $90 \%[28-31,35,37]$. Two authors did not state the percentage of children who required surgery $[29,32]$. Among the long-term group, the range is from 50 to $90 \%[27,31,33,34,36]$. It was not stated explicitly in most cases whether these procedures were for diagnostic or therapeutic purposes.

The number of children with septic arthritis in the short course group ranged from 0 to $40 \%[29,31,35,37]$. In 


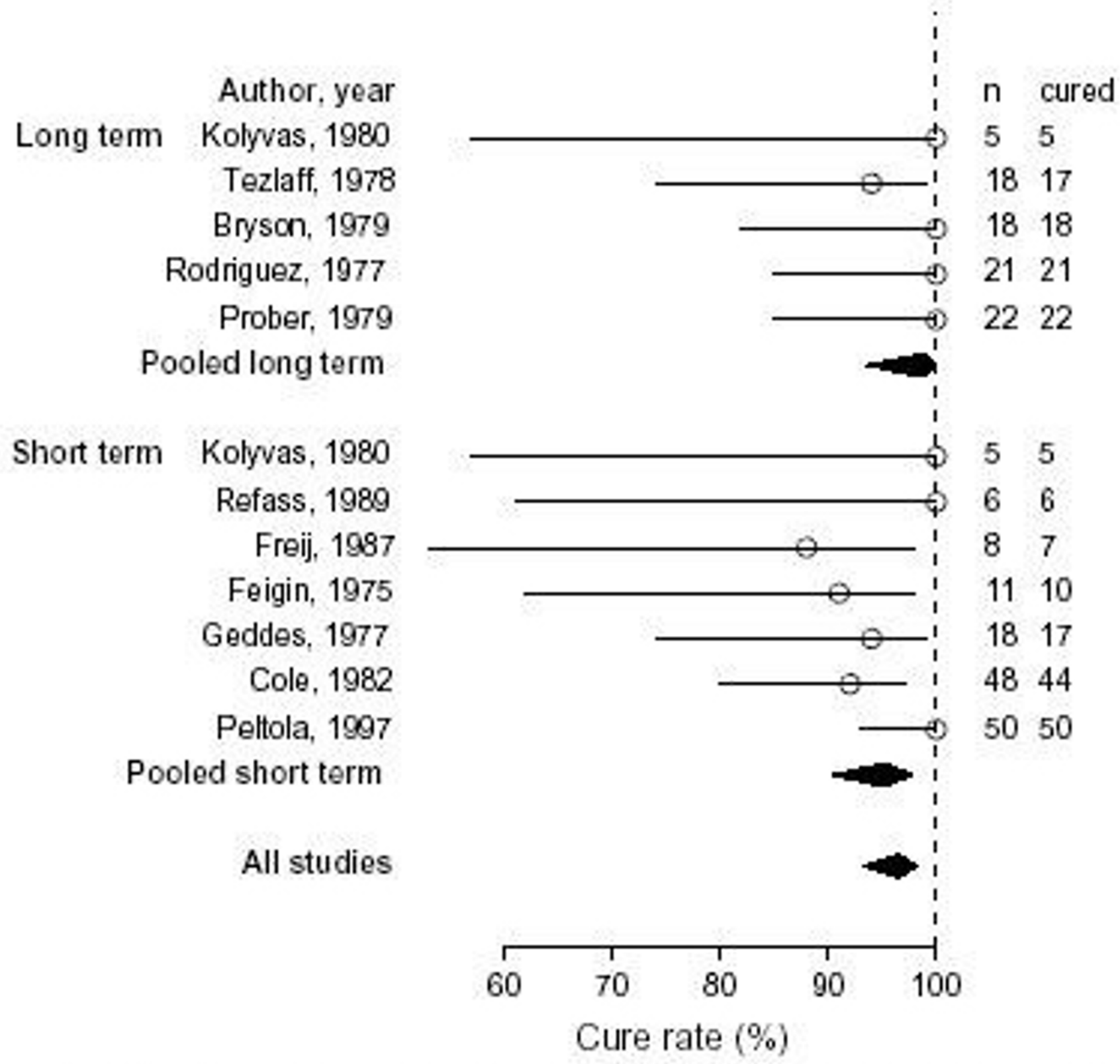

\section{Figure 2}

Cure rate versus the duration of parenteral antimicrobial therapy Long-term parenteral antimicrobials is defined as greater than or equal to 7 days. Short-term parenteral antimicrobials is defined as less than 7 days

three studies the exact number could be deduced, $[28,30,32]$ whereas in the 5 cohorts who were given greater than 7 days of therapy, $0 \%$ to $20 \%$ of children had concomitant septic arthritis [27,31,33,34,36].

\section{Discussion}

The epidemiology of childhood AHO has changed since routine childhood immunization against Haemophilus influenzae type b was introduced in the early 1990s [39].
Currently, the most common causative organism of childhood AHO is Staphylococcus aureus. For AHO therapy to be successful, levels of antimicrobial agents must be maintained sufficiently high over time to eliminate the bacteria from the site of infection. Pharmacologic evidence for adequate concentrations of oral antimicrobial agents in affected tissues supports the use of oral agents within a management scheme of 'step-down therapy.' [34,36] The benefits of shorter courses of parenteral antimicrobial 
therapy before switching to oral therapy include decreased costs and morbidity. There still exists, however, a dilemma with respect to the optimal duration of parenteral therapy.

Our systematic review of cohort studies using a minimum follow up of 6 months found a pooled cure rate of $95.2 \%$ $(95 \% \mathrm{CI}=90.4-97.7)$ with 7 days or less of parenteral therapy. Other cohorts that had short follow-up (therefore not included in our review) reported treating children with less than 7 days of parenteral antimicrobial reported cure rates of greater than $90 \%$; $[40,41]$. In one other cohort (not suitable for inclusion in our analysis due to unextractable data, heterogeneous group and a follow up period of 4 months), a 95\% cure rate was observed with 14 days of parenteral antimicrobial therapy [42]. Many other prospective studies could not be included in the systematic review for a variety of reasons: lack of standardized definitions, lack of retrievable treatment information or short follow-up periods $[2,19,40-49]$.

The small sample size used (mean of 24 patients; range 5 to 50 patients) is of concern although we gained statistical strength by pooling across studies. Thus, individual studies have wide confidence intervals, which are narrowed using the systematic review approach, providing a more precise estimate of the "true" cure rates (Figure 1). The range of duration of oral antimicrobial agents was also wide, implying that there may have been other clinical factors that were implicit in the decision of total length of therapy. Other clinical parameters, such as the extent of bone involvement, suspicion of septic arthritis and the course of the illness before treatment, may also have influenced treatment duration, but were not reported. Although the studies were prospective cohorts with respect to length of therapy they may be inherently biased in their selection criteria.

We did not assess the quality of reports of the included studies. Quality assessment is an important part of a systematic review, particularly if a validated approach is used [50]. We are unaware of any published assessment measure for cohort studies and elected to forgo the pitfalls of developing one ourselves [51].

Clinical heterogeneity in the data from older studies can be partly attributed to the multiple pathogens that were responsible for the clinical syndrome. Only one study was published after routine childhood immunization for Haemophilus influenzae type b was introduced in the early 90's [35]. We included children who had had disease due to Staphylococcus aureus as well as those who were culture negative because in many cases this reflects the reality of clinical practice. Studies that deal only with staphylococcal disease or that were published after 1990 from areas where there is universal immunization against Haemophilus influenzae type $\mathrm{b}$ are most likely to best represent the child who currently presents with AHO due to methicillin sensitive Staphylococcus aureus (MSSA).

Our review had several limitations. We narrowed our focus to cohort studies. Results from randomized controlled trials may provide more valid results and we are aware of the existence of at least one such study [38]. The cure rate of $91.6 \%$ in children who received short course parenteral therapy however supports the findings of this systematic review. This report however only included 12 children in that group. Combining this study with the cohort studies might introduce bias into the estimates of cure rates.

Our results indicate that cure rates are similar regardless of whether children with $\mathrm{AHO}$ are treated for a shorter or longer time period. There are several potential practical advantages of the shorter course of therapy; shorter hospital stay; decreased morbidity from intravenous lines and more cost effective. We believe that the results from this systematic review warrant serious consideration be given to conducting a randomized controlled trial. Such a study could be developed to demonstrate equivalence between two durations of antibiotic therapy: a shorter course (i.e., 3-5 days) compared to a more "standard" course of 14 to 21 days. This would only be relevant if cure rates were not equivalent. The results from such a study could be used to better inform clinicians as to the management of children with $\mathrm{AHO}$ in the future.

\section{Competing interests}

None declared.

\section{Authors' contributions}

NLS conceived of the study, participated in study design, reviewed trials for inclusion, abstracted data, participated in data analysis, and drafted the first manuscripts.

AH participated in initial study design, reviewed trials for inclusion, abstracted data, participated in data analysis, contributed to writing of the manuscript.

NJB planned and directed the statistical analyses, and participated in the drafting and revision of the manuscript.

IG extracted data from trials, carried out statistical analyses, and participated in the drafting and revision of the manuscript.

MS participated in the development of the literature search, interpretation of the results and preparation of the manuscript. 
DM supervised the systematic review and advised on methods issues.

All authors read and approved the final manuscript.

\section{Additional material}

\section{Additional file 1}

Contains= database names, dates searched, and search strings for the electronic search strategies.

Click here for file

[http://www.biomedcentral.com/content/supplementary/14712334-2-16-S1.doc]

\section{Acknowledgements}

We would like to thank Dr. Barbara Law and for helpful comments on an earlier draft of this manuscript.

\section{References}

I. Krogstad P, Smith AL: Steomyelitis and septic arthritis. In Textbook of pediatric infectious diseases. (Edited by: Feigin $R$, Cherry J) Philadelphia: W.B. Saunders Company 1998, 683-698

2. Unkila Kallio L, Kallio MJT, Peltola H: Acute hematogenous osteomyelitis in children in Finland. Ann Med 1993, 25:545-549

3. Nade S: Acute hematogenous Osteomyelitis in Infancy and Childhood. J Bone Joint Surg Br 1983, 65B:109-II9

4. Nelson J: Osteomyelitis and Suppurative Arthritis. In Nelson Textbook of Pediatrics. (Edited by: Behrman R.E., Kliegman R.M., Jenson H.B.) Philadelphia: W.B. Saunders Company 2000, 776-780

5. Gutierrez KM: Osteomyelitis. In Principles and Practice of Pediatric Infectious Diseases. (Edited by: Long SS, Pickering L.K., Prober C.G.) New York: Churchill Livingston Inc.; 1997, 528-537

6. Morrissy RT: Bone and joint sepsis. In Lovell and Winter's Pediatric Orthopedics. (Edited by: Morrissy R, Weinstein SL) Philadelphia: Lippincott Williams \& Wilkins; 200I, 459-503

7. Dich VQ, Nelson JD, Haltalin KC: Osteomyelitis in infants and children: a review of 163 cases. Am J Dis Child 1975, I29:12731278

8. Blockey NJ, Watson JT: Acute osteomyelitis in children. J Bone Joint Surg Br 1970, 52B:77-87

9. Jacobs RF, Augustine RA, Aronson J, McCarthy RE, Steele RW, Yamauchi T: Timentin therapy for bone, joint, and deep soft tissue infections in children. Am J Med I985, 79:।88-19|

10. Meller I, Manor Y, Bar-Ziv J, Torok G: Acute hematogenous osteomyelitis in children: long-term results of surgical treatment. Orthop Rev 1989, 18:824-831

II. Mollan R, Piggot J: Acute osteomyelitis in children. J Bone Joint Surg $\mathrm{Br}$ 1977, 9B:2-7

12. Bamberger T, Gugler E: [Acute osteomyelitis in childhood. A follow-up of predominantly conservatively treated children]. [German]. Schweiz Med Wochenschr 1983, I 13:1219-1228

13. Rud B, Halken S, Damholt V: Hematogenous osteomyelitis in children. Acto Orthop Scand 1986, 57:440-443

14. Syrogiannopoulos GA, Nelson JD: Duration of antimicrobial therapy for acute suppurative osteoarticular infections. Lancet 1988, 37-40

15. LaMont RL, Anderson PA, Dajani AS, Thirumoorthi MC: Acute hematogenous osteomyelitis in children. J Pediatr Orthop 1987, 7:579-583

16. Kandel SN, Mankin HJ: Pyogenic abscess of the long bones in children. Clin Orthop 1973, 96:108-117

17. Karwowska A, Davies HD, Jadavji T: Epidemiology and outcome of osteomyelitis in the era of sequential intravenous-oral therapy. Pediatr Infect Dis J 1998, I 7:1021-1026
18. Petersen S, Knudsen FU, Anderson EA, Egebald M: Acute haematogenous osteomyelitis and septic arthritis. Acto Orthop Scand 1980, 5 1:451-457

19. Dones P, Scarlata F, Di Gangi M: Effectiveness of teicoplanin as a monotherapy in the treatment of coagulase-positive Staphylococcus aureus in osteomyelitis. Mediterranean J of Infect \& Parasitic Dis 1994, 9:99-100

20. Arango JL, Trujillo H, Worren D, Uribe A, Agudelo NH, de Vidal EL: Effectiveness of two new cephalosporins, cephazolin and cephapirin, administered intermittently in acute and chronic osteomyelitis in children. J Int Med Res 1976, 4:183-194

21. Sadat-Ali M: Manage of acute osteomyelitis in children-should it be conservative? Indian J Med Sci 1992, 46:297-300

22. Highland TR, Lamont RL: Osteomyelitis of the pelvis in children. J Bone Joint Surg Am 1983, 65-A:230-234

23. Geissler WB, Purvis JM: Hematogenous osteomyelitis and septic arthritis in children: a ten year review. J Miss State Med Assoc 1989, 30:71-74

24. Green JH: Cloxacillin in treatment of acute osteomyelitis. $B M$ 1967, 2:4|4-4|6

25. Lane-O'Kelly A, Moloney AC: Acute haematogenous osteomyelitis - evaluation of management in the 1990s. Ir J Med Sci 1995, 164:285-288

26. Newcombe RG: Two-sided confidence intervals for the single proportion: comparison of seven methods. Stat Med 1998 , 1 7:857-872

27. Bryson YJ, Connor JD, LeClerc M, Giammona ST: High-dose oral dicloxacillin treatment of acute staphylococcal osteomyelitis in children. J Pediatr 1979, 94:673-675

28. Cole WG, Dalziel RE, Leitl S: Treatment of acute osteomyelitis in childhood. I Bone Joint Surg Br 1982, 64:2 18-223

29. Feigin RD, Pickering LK, Anderson D, Keeney RE, Shackleford PG: Clindamycin treatment of osteomyelitis and septic arthritis in children. Pediatrics 1975, 55:213-223

30. Freij BJ, Kusmiesz H, Shelton S, Nelson JD: Imipenem and cilastatin in acute osteomyelitis and suppurative arthritis. $\mathrm{Am} J \mathrm{Dis}$ Child 1987, |41:335-342

31. Kolyvas E, Ahronheim G, Marks MI: Oral antibiotic therapy of skeletal infections in children. Pediatrics $1980,65: 867-87 \mid$

32. Refass A, Harouchi A, Fehri M, El Andaloussi M, Bellamine A, Merini MF: The treatment of acute osteomyelitis in children by monoantibiotic therapy with flucloxacillin. Medecine et Maladies Infectieuses 1989, 19:96-100

33. Rodriguez W, Ross S, Khan W, McKay D, Moskowitz P: Clindamycin in the treatment of osteomyelitis in children. Am J Dis Child 2000, I 3 I: 1088-1093

34. Tetzlaff TR, McCracken GH, Nelson JD: Oral antibiotic therapy for skeletal infections in children. I Pediatr 1978, 92:485-490

35. Peltola H, Unkila Kallio L, Kallio MT, Aalto K, Anttolainen I, Fagerholm R, et al: Simplified treatment of acute staphylococcal osteomyelitis of childhood. Pediatrics 1997, 99:846-850

36. Prober CG, Yeager AS: Use of the serum bactericidal titer to assess the adequacy of oral antibiotic therapy in the treatment of acute hematogenous osteomyelitis. J Pediatr 1979 , 95: $131-135$

37. Geddes AM, Dwyer NSt], Ball AP, Amos RS: Clindamycin in bone and joint infections. J Antimicrob Chemother 1977, 3:501-507

38. Kaplan SL, Mason EOJ, Feigin RD: Clindamycin versus nafcillin or methicillin in the treatment of Staphylococcus aureus osteomyelitis in children. South Med J 1982, 75: I38-142

39. Howard AW, Viskontas D, Sabbagh C: Reduction in osteomyelitis and septic arthritis related to Haemophilus influenzae type B vaccination. J Pediatr Orthop 1999, 19:705-709

40. Nelson JD, Bucholz RW, Kunmiesz H, Shelton S: Benefits and risks of sequential parenteral-oral cephalosporin therapy for suppurative bone and joint infections. J Pediatr Orthop 1982, 2:255262

4I. Walker SH: Staphylococcal osteomyelitis in children: success with cephaloridine-cephalexin therapy. Clin Pediatr (Phila) 1973 I 2:98-100

42. Nussinovitch M, Shalit I, Einhorn M, Keren G, Rachmel A, Asia A, et al: Amoxicillin-clavulanate versus standard antibiotic therapy for the treatment of septic arthritis and osteomyelitis. Pediatrics \& Related Topics 1997, 36:73-82 
43. Beauvais P, Filipe G, Berniere J, Carlioz $\mathrm{H}$ : Oral pristinamycinum therapy for bone and joint infections in children. A report of $\mathbf{5 0}$ cases. Arch Fr Pediatr 198I, 38:489-493

44. Fleming PC, Huda SS, Bobechko WP: Cephaloridine and the penicillins in the treatment of staphylococcal osteomyelitis and arthritis. Postgrad Med J 1970, 89-93

45. Badelon O, Bingen E, Sauzeau C, Lambert-Zechovsky N, de Ribier A Bensahel $\mathrm{H}$ : [Choice of first-line antibiotic therapy in the treatment of bone and joint infections in children]. [French]. Pathol Biol (Paris) 1 988, 36:746-749

46. Kulhanjian J, Dunphy MG, Hamstra S, Levernier K, Rankin M, Petru A, et al: Randomized comparative study of ampicillin/sulbactam vs. ceftriaxone for treatment of soft tissue and skeletal infections in children. Pediatr Infect Dis J 1989, 8:605-610

47. Learmonth ID, Dall G, Pollock DJ: Acute osteomyelitis and septic arthritis in children. A simple approach to treatment. South African Medical Journal 1984, 65: I I7-120

48. Aronoff SC, Scoles PV, Makley JT, Jacobs MR, Blumer JL, Kalamchi A Efficacy and safety of sequential treatment with parenteral sulbactam/ampicillin and oral sultamicillin for skeletal infections in children. Rev Infect Dis 1986, 8:S639-S643

49. Unkila-Kallio L, Kallio MJ, Eskola J, Peltola H: Serum C-reactive protein, erythrocyte sedimentation rate, and white blood cell count in acute hematogenous osteomyelitis of children. Pediatrics 1994, 93:59-62

50. Moher D, Cook DJ, Jadad AR, Tugwell P, Moher M, Jones A, et al: Assessing the quality of randomized controlled trials: Implications for the conduct of meta-analyses. Health Technol Assess 1999, 3:1-98

5I. Marshall M, Lockwood A, Bradley C, Adams CE, Joy C, Fenton M: Unpublished rating scales: a major source of bias in randomized controlled trials of treatments for schizophrenia. British Journal of Psychiatry 2000, 176:249-252

52. Al-Harby S: Acute hematogenous osteomyelitis of childhood in Saudi Arabia. Why does treatment fail? Saudi Med J 1997, 18: $148-150$

53. Babaiantz P: [Acute osteomyelitis in infants and children. Follow-up study of $\mathbf{2 5}$ cases]. [French]. Schweiz Rundsch Med Prax 1975, 64:706-720

54. Dagan R, Phillip M, Watemberg NM, Kassis I: Outpatient treatment of serious community-acquired pediatric infections using once daily intramuscular ceftriaxone. Pediatr Infect Dis 1987, 6: 1080-1084

55. Dirschl DR: Acute pyogenic osteomyelitis in children. Orthop Rev 1994, 23:305-312

56. Hoffman EB, Knudsen CJ, Paterson MP: Acute osteomyelitis and septic arthritis in children: A spectrum of disease. Pediatr Surg Int 1990, 5:382-386

57. Jackson MA, Burry VF, Olson LC: Pyogenic arthritis associated with adjacent osteomyelitis: identification of the sequelaeprone child. Pediatr Infect Dis ] 1992, I I:9-13

58. Braun HS, Ender A, Friedel B: [Follow-up studies in infantile osteomyelitis]. [German]. Beitr zur Orthop Traumatol 1984, 3 I:305313

59. Aigner RM, Fueger GF, Vejda M: Follow-up of osteomyelitis of infants with systemic serum parameters and bone scintigraphy. Nucl Med (Stuttg) 1996, 35: I 16-121

60. Anderson JR, Scobie WG, Watt B: The treatment of acute osteomyelitis in children: A I 0-year experience. J Antimicrob Chemother 1981, 7:43-50

61. Craigen MAC, Watters J, Hackett JS: The changing epidemiology of osteomyelitis in children. J Bone Joint Surg Br 1992, 74:54I-545

62. Fink CW, Nelson JD: Septic arthritis and osteomyelitis in children. Clin Rheum Dis 1986, I 2:423-435

63. François P, Sarlangue J, Grimprel E, Carrieré JC, Garnier JM, De, et al: Epidemiology and bacteriological diagnosis of osteoarticular infections in children. A multicentric study (I). Medecine et Maladies Infectieuses 1992, 22:758-762

64. Gillespie WJ, Mayo KM: The management of acute haematogenous osteomyelitis in the antibiotic era. A study of the outcome. J Bone Joint Surg Br 1981, 63:126-131

65. Roine I, Arguedas A, Faingezicht I, Rodriguez F: Early detection of sequela-prone osteomyelitis in children with use of simple clinical and laboratory criteria. Clin Infect Dis 1997, 24:849-853
66. Scott RJ, Christofersen MR, Robertson WW Jr, Davidson RS, Rankin L, Drummond DS: Acute osteomyelitis in children: a review of I 16 cases. J Pediatr Orthop 1990, 1 0:649-652

67. Van Brederode NE, Ponsen RG: Acute haematogenic osteomyelitis. Ned Tijdschr Geneeskd 1980, I 24:453-455

68. Vaughan PA, Newman NM, Rosman MA: Acute hematogenous osteomyelitis in children. J Pediatr Orthop 1987, 7:652-655

69. Anderson JR, Orr JD, Maclean DA, Scobie WG: Acute haematogenous osteitis. Archives of Disease in Childhood 1980, 55:953-957

70. Faden H, Grossi M: Acute osteomyelitis in children. Reassessment of etiologic agents and their clinical characteristics. Am J Dis Child 1991, 145:65-69

7I. Gillespie WJ: Late recurrence following acute haematogenous osteomyelitis. New Zealand Medical Journal 1975, 82:304-305

72. Trujillo H, Alvarez RM, Rodriguez AB, Roldán RF, Warren DS, Gil HL, et al: La rifampicina y las penicinas en el tratamiento de las osteomielitis hematogenas de los niño. Antioquia Medica 1974 24:443-452

\section{Pre-publication history}

The pre-publication history for this paper can be accessed here:

http://www.biomedcentral.com/1471-2334/2/16/prepub
Publish with BioMed Central and every scientist can read your work free of charge

"BioMedcentral will be the most significant development for disseminating the results of biomedical research in our lifetime."

$$
\text { Paul Nurse, Director-General, Imperial Cancer Research Fund }
$$

Publish with BMC and your research papers will be:

- available free of charge to the entire biomedical community

- peer reviewed and published immediately upon acceptance

- cited in PubMed and archived on PubMed Central

- yours - you keep the copyright editorial@biomedcentral.com 